\title{
Are reservoir earthquakes man-made?
}

\author{
Y. L. Shi, H. H. Cheng, B. Zhang, L. Zheng, Y. J. Sun \& H. Zhang \\ Key Laboratory of Computational Geodynamics of Chinese Academy of \\ Sciences, University of Chinese Academy of Sciences, Beijing, China
}

\begin{abstract}
A debate on whether the Wenchuan Mw7.9 earthquake is triggered by the nearby Zipingpu reservoir has drawn the attention of both the scientific community and the general public. High performance computation provides a powerful new tool to quantitatively evaluate stresses produced by the weight of impoundment of reservoirs and the changes of pore pressure due to water diffusion along faults to the hypocenter. We calculated Coulomb stress changes of a number of reservoirs: including the hotly debated Zipingpu reservoir, the well known reservoir earthquake of Xinfengiiang in 1962, and the reservoir earthquake of Aswan in 1981. We have reached several main conclusions: Elastic energy increase due to the weight of impounded water is usually very small in comparison with seismic wave energy released by earthquakes of magnitude 6 or greater, these reservoir earthquakes are improper to be called man-made, but they are human activity triggered. Geological background and tectonic stresses control the occurrence of such large reservoir earthquakes. Stresses due to weight of impoundment may promote or prevent the occurrence of reservoir earthquakes determined by the location and nature of the earthquake fault. Pore pressure increase due to water penetration along permissive fault, however, always increases the risk of reservoir earthquakes. There seems no definite threshold value of Coulomb stress to trigger earthquake, it may varies from several $\mathrm{kPa}$ to $0.1 \mathrm{MPa}$, depending on the magnitude of tectonic stresses and strength of the fault. The occurrence time of reservoir earthquakes after impoundment also varies from months to years depending on the permeability and stress of the fault zone. Geological surveys and numerical simulations may improve risk estimates before reservoir construction.

Keywords: reservoir-triggered earthquake, Coulomb failure stress (CFS), Zipingpu reservoir, Wenchuan earthquake, Xinfengjiang reservoir, Aswan reservoir.
\end{abstract}




\section{Introduction}

Genesis of reservoir triggered earthquake (RTE) is an important problem and has drawn a lot of attentions [1-6]. A debate has lasted five years about if the Mw7.9 Wenchuan earthquake, May 12, 2008, is related to impoundment of the Zipingpu Reservoir or not, since the reservoir is only about $10 \mathrm{~km}$ from the epicenter. Soon after the occurrence of Wenchuan earthquake, Fan [7] claimed that the Zipingpu earthquake might have triggered the Wenchuan earthquake based on qualitative criterion. Lei et al. [8] estimated the impact of the impoundment of Zipingpu reservoir to the Wenchuan earthquake through calculating the changes of Coulomb failure stress $(\Delta \mathrm{CFS})$. They drew the conclusion that Zipingpu reservoir acts an obvious impact on Longmenshan faults and the $\triangle \mathrm{CFS}$ of the coseismic fault is larger than $0.1 \mathrm{MPa}$ in the upper $10 \mathrm{~km}$ below the reservoir and a few tens of $\mathrm{kPa}$ at the focal depth, which means the Zipingpu reservoir could induce the occurrence of Wenchuan earthquake. Kerr and Stone [9] reported this kind of opinions. It is then interpreted as "Chinese earthquake may have been man-made, say scientists" by the news media (http://www.telegraph.co.uk/ news/worldnews/asia/china/4434400/Chinese-earthquake-may-have-been-manmade-say-scientists.html). A senior Chinese scientist Chen [10] diametrically opposed to this view and qualitatively discussed five features of the Wenchuan earthquake which are not consistent with the typical characters of common reservoir triggered earthquakes. However, qualitative arguments could not convince either side, the debate had been going on. Quantitative analysis is necessary. Unfortunately, although many researchers studied on this issue, their quantitative results are different, because of differences in models, parameters and methods of computation. For example, Ge et al. [11] used 2-D numerical models to calculate pore pressure and static load, they concluded that the impoundment of the Zipingpu reservoir changed the $\triangle \mathrm{CFS}$ by -0.01 to $0.05 \mathrm{MPa}$ at the earthquake hypocentre and potentially hastened the occurrence of this earthquake by tens to hundreds of years. Using 3-D analysis method, Ghaulaut and Ghaulaut [12] suggested that the reservoir produces negative Coulomb stress about $-0.1 \mathrm{kPa}$, therefore, plays no role in the occurrence of the earthquake. Deng et al. [13] used 2-D model to calculate the pore pressure with grid size greater than $1 \mathrm{~km}$, and analytical solution for a 3-D static load; they concluded that at the focal depth, $\triangle \mathrm{CFS}$ is $0.01 \mathrm{kPa}$, and therefore negligible. Lei [14] insisted his results that Coulomb stresses reach a few tens of $\mathrm{kPa}$ at the focal depth, and they are large enough to modulate the secular stress buildup of a few $\mathrm{kPa} / \mathrm{yr}$ in the Longmenshan thrust zone. Facing the divergences in computation, we need do more detailed investigation on the reservoir triggered earthquake. Firstly, we calculate numerical solution by finite element method (FEM) of simple problems and compare them with analytic solutions as benchmark to guarantee the code is valid and sufficient number of element is used for accuracy. Secondly, we discussed the difference between $2 \mathrm{D}$ and 3D. Then, by taking the consideration of the precise topography and dynamic water level, a three-dimensional poroelastic finite element model was constructed about Zipingpu reservoir. Finally, for comparison, we also applied the poroelastic FEM to the $M_{L} 5.7$ 
earthquake in Aswan reservoir in 1984 and the Ms6.1 earthquake in Xinfengjiang reservoir in 1962, which is well accepted as the largest reservoirinduced earthquake in China.

\section{The physical mechanism of RTE}

After the impoundment of reservoir, changes in stresses and pore pressure may influence the earthquake occurrence of the region originally under significant tectonic stresses. We adopt here Coulomb failure stress changes ( $\triangle \mathrm{CFS})$ to quantify the influence of the reservoir on the earthquakes. The $\Delta \mathrm{CFS}$ formula can be expressed as eqn (1) (Shi and Cao [15]).

$$
\Delta C F S=\Delta \tau+\mu\left(\Delta \sigma_{n}+\Delta P\right)
$$

where, $\Delta \sigma_{v}$ is the normal stress change and $\Delta \tau$ is shear stress change along the fault slip direction, $\mu$ the friction coefficient, following the principle of elasticity, tensile stress is positive in this paper. $\Delta \mathrm{P}$ is the pore pressure change, increase of pore pressure is expressed as positive. A positive $\triangle \mathrm{CFS}$ is in favor of the fault slip, and negative $\triangle$ CFS means the fault becomes safer.

The rock mass and faults are poroelastic. When large reservoirs are built, three main physical mechanisms may affect the Coulomb stresses on the nearby fault: (1) elastic load due to the weight of reservoir water; (2) pore pressure increase responding to the volumetric compression; (3) diffusive pore pressure change with time. $\triangle \mathrm{CFS}$ is affected by the three contributions and is used to study the trend whether the fault becomes safer or more risky [1, 11-13, 16-18].

\subsection{The effect of elastic load of impoundment and drainage of Zipingpu reservoir}

\subsubsection{Using analysis method to estimate the magnitude of $\triangle \mathrm{CFS}$ due to the elastic load}

Because different authors report Coulomb stresses at different order of magnitude, therefore we first approximate the reservoir water load as a point load to see the overall stress state at the focal depth before we go to detailed numerical study. Based on the solution of Boussinesq's problem, the result indicates (Figure 1) that the $\triangle \mathrm{CFSs}$ for thrust fault beneath the reservoir are mostly negative and decays rapidly with distance and depth to the load. The negative $\triangle$ CFS means the vertical compressive stress actually prevent the slip of thrust. At the hypocenter by CEA (China Earthquake Administration), the normal stress, shear stress and $\triangle \mathrm{CFS}$ are $-1.6,-2.8$ and $-3.8 \mathrm{kPa}$, respectively. These values give a reference level to benchmark the numerical computations.

The point load model can not reflect the complex stress changes within a few kilometers below reservoir. According to digital topography, we build a model with consideration of geometry of the reservoir and realistic water depth. We divided the Zipingpu reservoir into 2000 girds and integrate the point load at each grid. The results provide a more realistic view of stress distribution near the reservoir. Figure 2 shows Coulomb stress changes due to unloading, because the water level in the Zipingpu reservoir was reduced 80 meters 4 months before the 
main shock. The results confirms previous $\triangle \mathrm{CFS}$ computations, that at the focal depth, elastic loading tend to prevent the thrust slip and drainage of Zipingpu reservoir is in favor of the occurrence of the earthquake. The magnitude of the $\triangle \mathrm{CFS}$ decays rapidly with depth, is about $3 \mathrm{kPa}$ at the hypocenter.
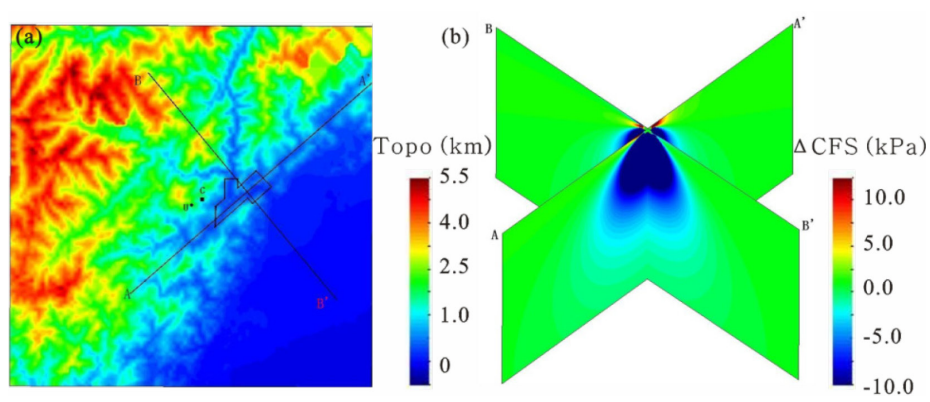

Figure 1: (a) the topography of Zipingpu reservoir area; (b) the $\triangle \mathrm{CFS}$ of profile AA' and BB'; Point U stands for the focus provided by USGS and Point $\mathrm{C}$ stands for the focus by CEA (China Earthquake Administration); the site of Zipingpu dam was the interaction of the profile AA' and BB'; the capacity of Zipingpu is $1.112 \mathrm{~km}^{3}$ and the height of dam is $156 \mathrm{~m}$ and the reserve-water-level is $877 \mathrm{~m}$; the horizontal scale is $100 \mathrm{~km}$ and the vertical scale is $50 \mathrm{~km}$ [19].

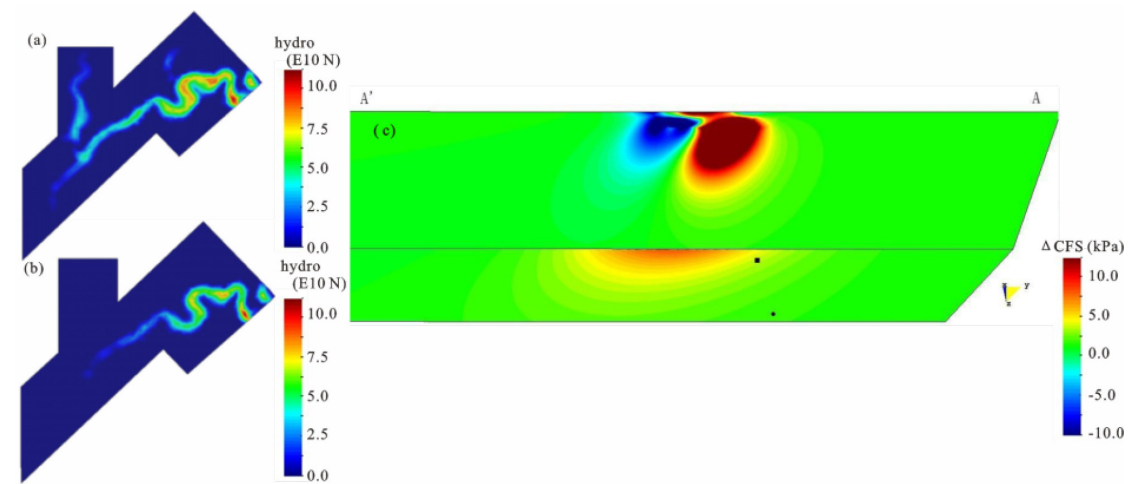

Figure 2: (a) hydraulic pressure when Zipingpu reservoir water level is $877 \mathrm{~m}$; (b) hydraulic pressure when Zipingpu reservoir water is $817 \mathrm{~m}$; (c) the $\triangle \mathrm{CFS}$ of the faults when water level reduced from $877 \mathrm{~m}$ to $817 \mathrm{~m}$; profile AA' stand for the direction of the seismic fault [19].

\subsubsection{Comparison of numerical method with analytic method}

Using half elastic space analytic method, results can be quickly attained. However, for consideration of more realistic data with heterogeneous geological features such as fault zones, strata, and topography, 3-D numerical model are 
necessary. We build 3-D models and compare the simple ones with analytic solution to guarantee sufficient accuracy of the code. Triangular prism elements were used in the FEM mesh; it is divided into twenty-seven layers and encrypted in the reservoir area. Total number of elements exceeds 910,000. Figure 3 shows the model and the calculated $\triangle \mathrm{CFS}$ at two profiles. The value of $\triangle \mathrm{CFS}$ at focal depth below the reservoir is also negative about $3.0 \mathrm{kPa}$, consistent with the analytic results.

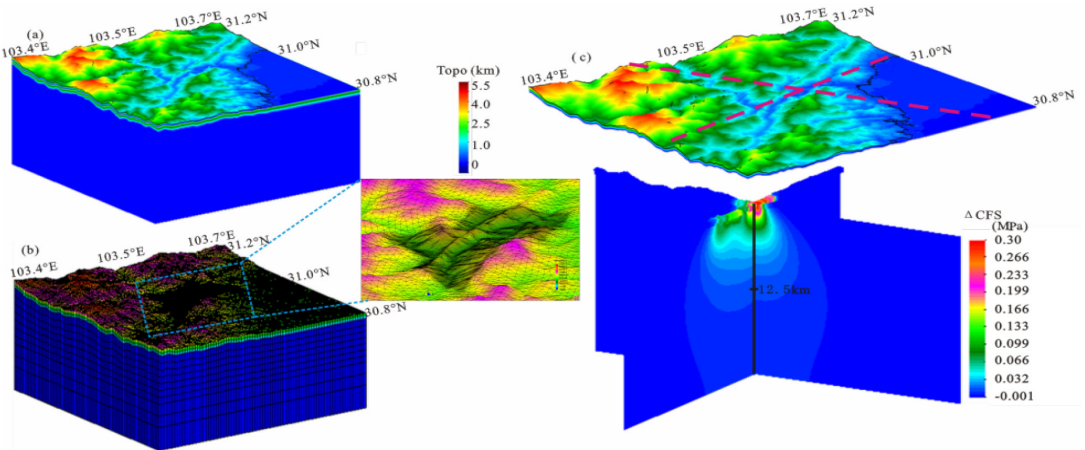

Figure 3: The 3D FEM model of Zipingpu Reservoir. (a) The 3D model and topography; (b) the FEM model mesh in the Zipingpu reservoir area; (c) the $\triangle \mathrm{CFS}$ at the two profiles labeled above [20].

According to the above results, we can confirm that the impoundment of Zipingpu reservoir make the coseismic fault more stable, while rapid water level decline make the fault more fragile. The magnitude of Coulomb stresses at focal depth due to elastic loading is about a few $\mathrm{kPa}$.

\subsection{The effect of Zipingpu Reservoir on the Wenchuan earthquake}

Based on above description and discussion, a 3D poroelastic FEM model of the Zipingpu area is constructed to calculate the complete effects of elastic loading and pore pressure during the entire operation of the reservoir. The model includes the fault zone, topography, heterogeneous geological survey data, and dynamic water level change of the Zipingpu reservoir from the beginning of the impoundment to the occurrence of the Wenchuan earthquake (Figure 4). Hydraulic parameters, especially diffusion coefficient and permeability are very important. Though drilling and other exploration can provide some parameters of the shallow rock mass, however, the deep parameters are not clear. Therefore, within a reasonable range, models of different diffusivity of faults and rock mass are calculated and compared to investigate their influences. The results show that the elastic modulus has little effect on the Coulomb stress, while the $\triangle \mathrm{CFS}$ at the hypocenter increase with the increase of diffusivity, as shown in Figure 4(b) and 4(c). If fault diffusivity exceeds $5.0 \mathrm{~m} / \mathrm{s}, \triangle \mathrm{CFS}$ at the hypocenter can reaches $\sim+1 \mathrm{kPa}$ on the eve of the Wenchuan earthquake occurrence. Otherwise, the $\triangle \mathrm{CFS}$ is negative. It is noticed that elastic contribution of impoundment of water 
makes the thrust fault more stable, but drainage of water is in favor of trigger the slip. While diffusive increase of pore pressure always tend to increase the seismic risk. It is interesting that the sudden increase of Coulomb stress before the Wenchuan earthquake is directly related to the drainage of water level 5 months before the quake. Figure 4(c) show that the distributions of small earthquakes around the Zipingpu area after the impoundment. They show a tendency occurring in region of increased positive Coulomb stress. Our results indicate the Zipingpu reservoir may not trigger the Wenchuan earthquake if the fault permeability is not sufficiently high. Even the permeability is high enough, however, it is still in doubt that if a small increase in $\triangle \mathrm{CFS}$ of $+1 \mathrm{kPa}$ can trigger the occurrence of the Wenchuan earthquake.
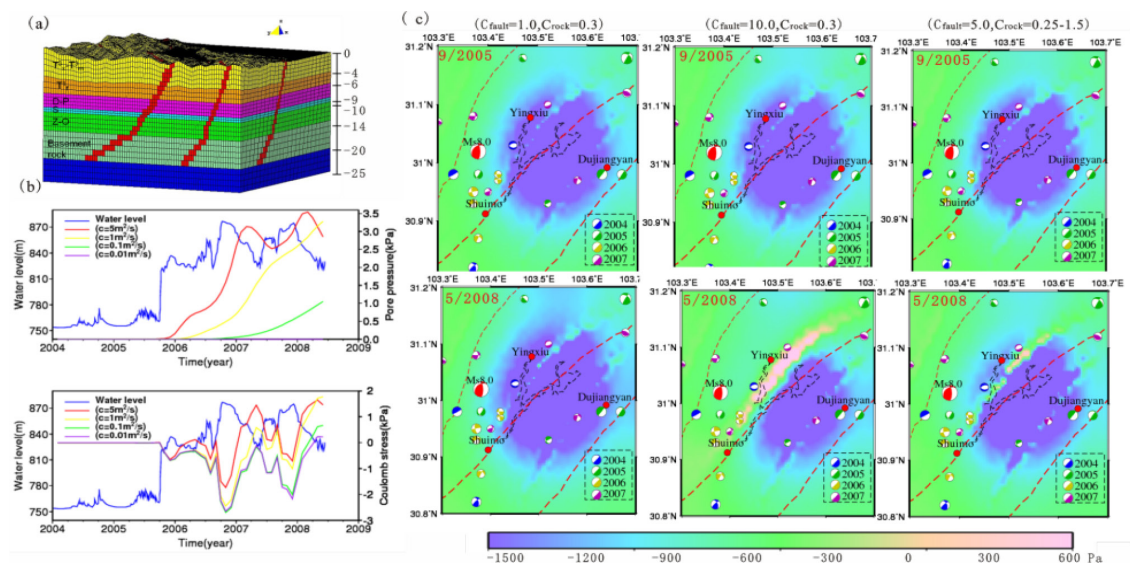

Figure 4: The 3D FEM model of Zipingpu area and the results of calculation; (a) the FEM model mesh in the Zipingpu reservoir area; (b) variation of pore pressure and $\triangle \mathrm{CFS}$ with the water level at the hypocenter of Wenchuan earthquake [21]; (c) distribution of $\triangle \mathrm{CFS}$ at the depth of $13 \mathrm{~km}$ for different combination of fault and rock properties, with small earthquakes from 2004 to 2008 labeled.

\subsection{The differences between $2 D$ and 3D}

Some researchers based on 2D model to analyze the influence of reservoir on the occurrence of the earthquake are in favor of the possibility of the Zipingpu reservoir triggering $[11,19]$. Actually, the 2D model means taking infinite linear loads instead of a load in limited area. It may exaggerate the loading effect. Using FEM method, we compare the differences of 2D and 3D models. Figure 5 shows that the results of $3 \mathrm{D}$ model is only $1 / 3$ to $1 / 4$ of that of $2 \mathrm{D}$ model. At the same time, we found that the results of $2 \mathrm{D}$ model are more sensitive to the diffusion coefficient. When we choose different diffusion coefficients, the difference of peak pore pressure in $2 \mathrm{D}$ and $3 \mathrm{D}$ are 10 and $2 \mathrm{kPa}$, respectively. So, using the $3 \mathrm{D}$ model is more reasonable in the absence of the measured diffusion coefficient. 

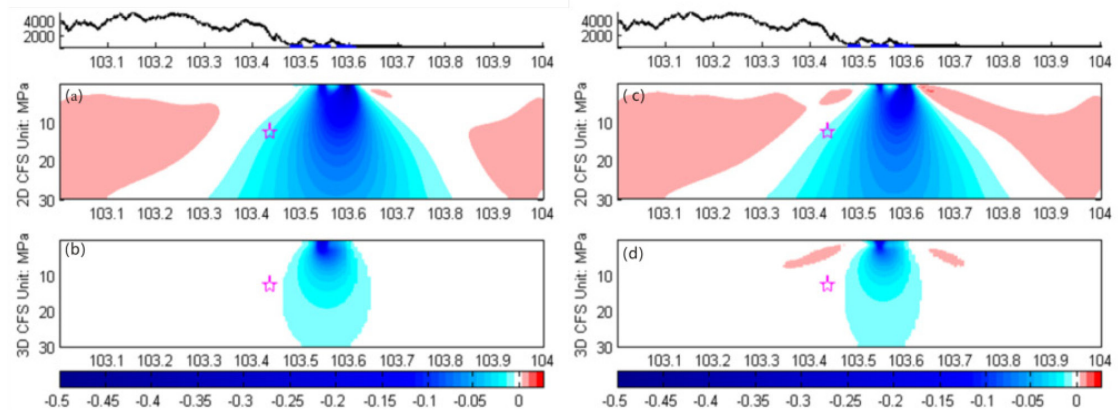

Figure 5: The differences between the 2D and 3D models; (a) the $\triangle \mathrm{CFS}$ due to the elastic load only in 2D; (b) the $\triangle \mathrm{CFS}$ due to the elastic load only in $3 \mathrm{D}$; (c) the $\triangle \mathrm{CFS}$ due to the elastic load and pore pressure in $2 \mathrm{D} ;(\mathrm{d})$ the $\triangle \mathrm{CFS}$ due to the elastic load and pore pressure in $3 \mathrm{D}$ [22].
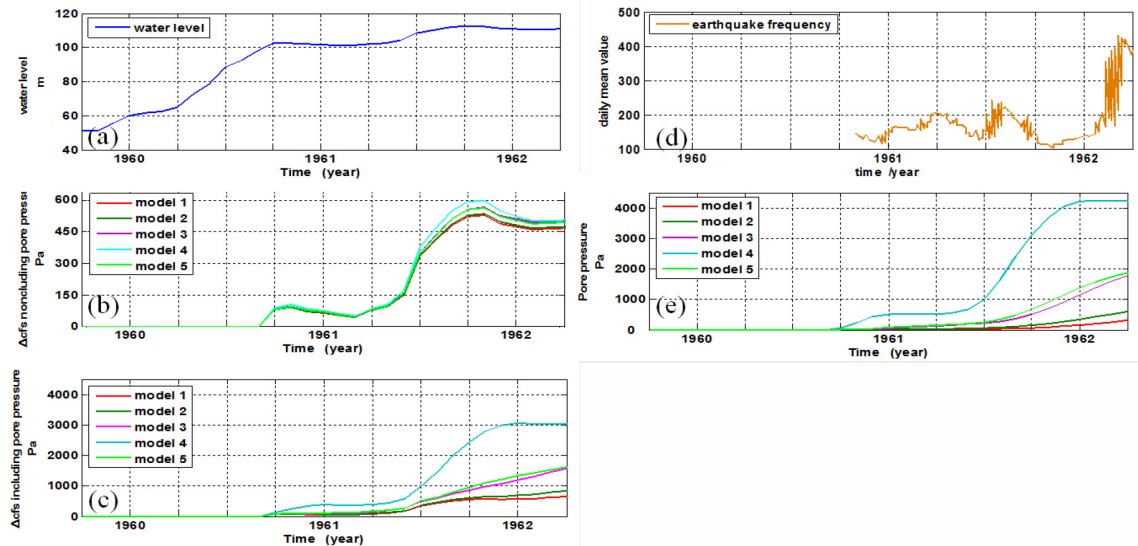

Figure 6: Variation of pore pressure and Coulomb stress with changing water level at the Ms6.1 hypocentre in Xinfengjiang Reservoir area. (a) Xinfengjiang Reservoir water level; (b) Coulomb stress due to elastic load only (pore pressure not included); (c) Coulomb stress at the focal depth; (d) the earthquake frequency in Xinfengjiang Reservoir area; (e) the pore pressure changes at the seismic source [23].

\subsection{The effect of Xinfengjiang reservoir on Ms6.1 earthquake}

Coulomb stress calculation of Zipingpu reservoir is marginal positive in favorable permeability conditions. For comparison, we try several other reservoirs to investigate if Coulomb stress needs to reach some threshold value to trigger reservoir earthquakes. Frequent seismic activities occurred since the 
impoundment of the Xinfengjiang Reservoir, Guangdong, China in October 1959. Two and half years later, an Ms 6.1 earthquake broke on 19 March 1962, well acknowledged as the largest reservoir-induced earthquake in China. A 3-D Xinfengjiang model was established. The diffusion coefficients of stratum in Xinfengjiang are uncertain. On the basis of the predecessors' study, we give five models of different diffusivity to discuss the effect of the impoundment of Xinfengjiang reservoir on the Ms6.1 earthquake.

The variations of pore pressure and $\triangle \mathrm{CFS}$ with water level are both increased with increasing water level, shown in Figure 6. Permeability of rock and fault plays a significant role in the pore pressure pervasion. Elastic stress induced by the water load had only a little effect on the stability of the fault system. Pore pressure makes the main contribution to changes of Coulomb stress. The $\triangle \mathrm{CFS}$ at the hypocenter was $0.7 \sim 3.0 \mathrm{kPa}$ in different models.

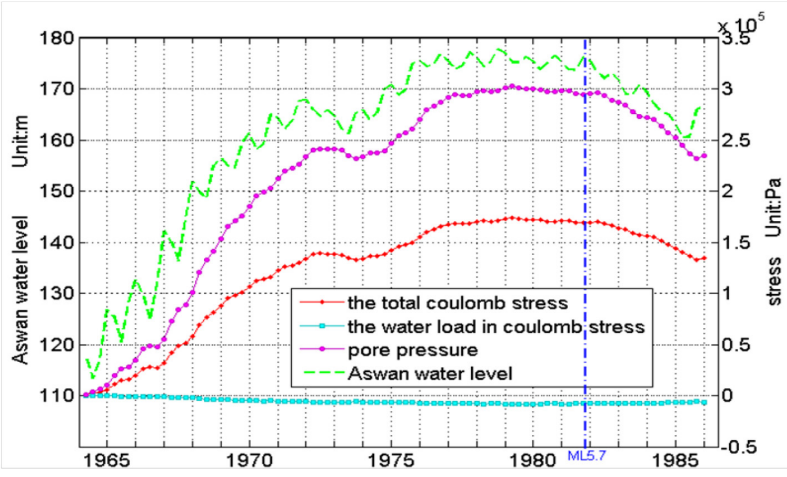

Figure 7: Variations of pore pressure and $\triangle \mathrm{CFS}$ at the hypocenter with changing water level [20].

\subsection{The $M_{L} 5.7$ earthquake in Aswan reservoir}

The Aswan Reservoir, the world's second largest reservoir, is located in southern Cairo in Egypt. The first impoundment of the Aswan Reservoir occurred in 1964 [24]. Maximum water depth was up to $177.48 \mathrm{~m}$ in November 1978. On November 14, 1981, four days after the water level reached seasonal maximum, an $\mathrm{M}_{\mathrm{L}} 5.7$ earthquake occurred. Three large foreshocks and two aftershocks occurred following the main shock. Faults are well developed in the reservoir area. A 3D Aswan Reservoir FEM poroelastic model was established. Figure 7 shows variations of pore pressure and $\triangle \mathrm{CFS}$ of the hypocenter. The pore pressure is about $300 \mathrm{kPa}$ at the time of the occurrence of $\mathrm{M}_{\mathrm{L}} 5.7$ earthquake. $\triangle \mathrm{CFS}$ caused only by reservoir loads is negative and relatively small compared with pore pressure. $\triangle \mathrm{CFS}$ reaches $0.17 \mathrm{MPa}$ before the main shock. Moreover, a dynamic lag in pore-pressure diffusion is encountered and is found to correspond with reservoir water level. Aswan Reservoir water level reached a peak in 1972, and pore pressure and $\triangle \mathrm{CFS}$ corresponding to the peak reached their highest points in 1973. 


\section{Is there a threshold value of $\triangle \mathrm{CFS}$ to trigger earthquake?}

King et al. [25] suggested that notable seismic activity could be observed if the stress change reaches $0.01 \mathrm{MPa}$, or $10 \mathrm{kPa}$. In this study, for Zipingpu, Xinfengjiang and Aswan reservoir, the values of $\triangle \mathrm{CFS}$ at the hypocenters immediately before the earthquake are about $1.0 \mathrm{kPa}, 3.0 \mathrm{kPa}$ and $100 \mathrm{kPa}$, respectively. The time interval between the impoundment of reservoir and the earthquake occurrence varies from several months to nearly 17 years. Although the Ms6.1 earthquake in Xinfengjiang reservoir area is widely accepted as the largest reservoir earthquake in China, the magnitude of the $\triangle \mathrm{CFS}$ in our model is $3.0 \mathrm{KPa}$ only, smaller than the $10 \mathrm{kPa}$ value proposed by King. While the Aswan earthquake did not occur until the Coulomb stress increased to $100 \mathrm{kPa}$ after 17 years. Therefore, it seems that there is no definite threshold value for triggering reservoir earthquakes. The occurrence of reservoir triggered earthquakes is closely related to the background tectonic stress field and fault or rock strength. Even though the $\triangle \mathrm{CFS}$ is small, if tectonic stresses are already close to the strength, reservoir impoundment and drainage can trigger reservoir earthquakes. Therefore, in the future study of RTE, state of tectonic stresses should be explored carefully.

\section{Strain energy due to the impoundment of reservoir}

The impoundment of reservoir could lead to rock mass deformation. So we can calculate the elastic strain energy produced by water loading, and it can be compared with seismic wave energy released during the earthquake. We calculated the maximum vertical subsidence due to impoundment of Xinfengjiang reservoir is $17.5 \mathrm{~mm}$, in well agreement with the observed $15.0 \mathrm{~mm}$. The strain energy induced by Zipingpu, Xinfengjiang and Aswan reservoir are about $4.0 \times 10^{11} \mathrm{~J}, 7.3 \times 10^{11} \mathrm{~J}$ and $1.12 \times 10^{15} \mathrm{~J}$, respectively, comparing with the energy released by the seismic wave energy of Mw7.9, Ms6.1 and $\mathrm{M}_{\mathrm{L}} 5.7$ earthquakes, they are less than $0.001 \%, 1 \%$ and $0.01 \%$. This result shows that the impoundment of the reservoir only triggered the earthquake. Most energy released by the earthquake has been stored there due to tectonic loading for tens or hundreds of years. The reservoir triggered earthquake with magnitude 6.0 or greater cannot be called man-made. They are only triggered by human activity.

\section{Discussion and conclusion}

Since Carder [2] investigated the relationship between the Denver Reservoir and local earthquake activity in the 1940s, many scientists have focused on reservoir triggered seismicity and obtain some physical mechanisms of RTE [1-6, 26-27]. However, after the $M w 7.9$ Wenchuan earthquake, there exists a heated argument about whether the Zipingpu reservoir triggered the occurrence of the Wenchuan earthquake [9-14, 28-30]. We therefore carried out investigations on the reservoir triggered earthquake by constructing numerical models and calculating the $\Delta$ CFSs for the $M w 7.9$ Wenchuan earthquake, Ms6.1 Xinfengjiang earthquake 
and $M_{L} 5.7$ Aswan earthquake. We get the following conclusions: (1) the direct elastic effect of impoundment loading at Zipingpu reservoir makes the thrust fault more stable, while rapid water level decline make the fault more fragile. (2) Pore pressure increases due to water penetration along permeable fault, always increases the risk of reservoir earthquakes. Diffusivity of fault zones is of critical importance. (3) With reasonable values of diffusivity, we found the $\triangle \mathrm{CFS}$ at the hypocenter of Wenchuan earthquake ranges at a marginal value from a few $\mathrm{kPa}$ negative to only $\sim+1 \mathrm{kPa}$ on the eve of the Wenchuan earthquake occurrence. There is no solid evidence to support that Wenchuan earthquake is triggered by the Zipingpu reservoir impoundment, however, it is also too early to exclude the possibility of triggering effect, because the Coulomb stress may be positive in favorable conditions, and the earthquake occurred when drainage rapidly after a long period of high water level. (4) For $M s 6.1$ Xinfengjiang earthquake, the reservoir impounding increases both the pore pressure and $\triangle \mathrm{CFS}$. The diffusion of pore pressure is the main factor that triggered earthquake, while the elastic water load is small. The $\triangle \mathrm{CFS}$ values at the hypocenter can be about $3.0 \mathrm{kPa}$, depending on the fault diffusivity. In Aswan reservoir area, both pore pressure and Coulomb stress of seismogenic fault have been gradually increasing with the raising water level, and the maximum values can reach $0.01 \mathrm{MPa}$ to trigger the earthquake. (5) Coulomb stresses calculated from $2 \mathrm{D}$ model have been exaggerated. For the case of Zipingpu reservoir, the results of $3 \mathrm{D}$ models are only $1 / 3$ to $1 / 4$ of those of $2 \mathrm{D}$ models. (6) The elastic strain energy due to reservoir impoundment is very small compared with seismic wave energy for earthquakes of magnitude 6 or greater. Therefore major reservoir earthquakes are triggered by water impoundment, but it is improper to call them man-made. (7) There seems no definite threshold value of Coulomb stress to trigger earthquake, it may varies from several $\sim \mathrm{kPa}$ to $0.1 \mathrm{MPa}$, depending on the magnitude of tectonic stresses and strength of the fault. The occurrence time of reservoir earthquakes after impoundment also varies from months to years depending on the permeability and stress of the fault zone. (8) Geological surveys, stress measurement and numerical simulations may improve risk estimates before reservoir construction.

\section{Acknowledgement}

This research is supported by the Deep Crust exploration Project in China (SinoProbe-07).

\section{References}

[1] Bell, M. L. and Nur, A., Strength changes due to reservoir-induced pore pressure and stresses and application to Lake Oroville. Journal of geophysical research, 83(B9) pp. 4469-4483, 1978.

[2] Carder, D. S., Seismic investigations in the Boulder Dam area, 1940-1944, and the influence of reservoir loading on local earthquake activity. Bulletin of the Seismological Society of America, 35(4), pp. 175-192, 1945. 
[3] Nur, A. and Booker, J. R., Aftershocks caused by pore fluid flow?. Science, 175(4024), pp. 885-887, 1972.

[4] Rice, J. R. and Cleary, M. P., Some basic stress diffusion solutions for fluid - saturated elastic porous media with compressible constituents. Reviews of Geophysics, 14(2), pp. 227-241, 1976.

[5] Roeloffs, E. A., Fault stability changes induced beneath a reservoir with cyclic variations in water level. Journal of Geophysical Research, 93(B3), pp. 2107-2124, 1988.

[6] Simpson, D. W., Leith, W. S. and Scholz, C. H., Two types of reservoirinduced seismicity. Bulletin of the Seismological Society of America, 78(6), pp. 2025-2040, 1988.

[7] Fan X., Underground secret of the Wenchuan Earthquake. Chinese National Geographic, (6), pp. 101- 139, 2008.

[8] Lei, X. L. and Ma, S. L., et al. Integrated analysis of stress and regional seismicity by surface loading - a case study of Zipingpu reservoir. Seismology and Geology, 30(4), pp. 1046-1064, 2008.

[9] Kerr, R. A. and Stone, R., A human trigger for the great quake of Sichuan?. Science, 323(5912), pp. 322-322, 2009.

[10] Chen, Y., Did the reservoir impoundment trigger the Wenchuan earthquake?. Science in China Series D: Earth Sciences, 52(4), pp. 431433, 2009.

[11] Ge, S. and Liu, M., et al. Did the Zipingpu Reservoir trigger the 2008 Wenchuan earthquake?. Geophysical Research Letters, 36(20), 2009.

[12] Gahalaut, K. and Gahalaut, V. K., Effect of the Zipingpu reservoir impoundment on the occurrence of the 2008 Wenchuan earthquake and local seismicity. Geophysical Journal International, 183(1), pp. 277-285, 2010.

[13] Deng, K. and Zhou, S Y., et al. Evidence that the $2008 \mathrm{Mw} 7.9$ Wenchuan earthquake could not have been induced by the Zipingpu Reservoir. Bulletin of the Seismological Society of America, 100(5B), pp. 2805-2814, 2010.

[14] Lei, X., Possible roles of the Zipingpu Reservoir in triggering the 2008 Wenchuan earthquake. Journal of Asian Earth Sciences, 40(4), pp. 844-854, 2011.

[15] Shi, Y. L. and Cao, J. L., Some aspects in static stress change calculation case study on Wenchuan earthquake. Chinese J Geophys, 53(1), pp. 102$110,2010$.

[16] Chen, L. and Talwani, P., Reservoir-induced seismicity in China. Pure and Applied Geophysics, 153(1), pp. 133-149, 1998.

[17] Talwani, P., Chen, L. and Gahalaut, K., Seismogenic permeability, ks. Journal of Geophysical Research: Solid Earth (1978-2012), 112(B7), 2007.

[18] Wang, C. and Manga, M., Earthquakes and water. Springer Verlag, 2010.

[19] Zhang, B. and Shi, Y. L., A discussion on the influences of Zipingpu reservoir on the stability of faults in the neighborhood. J Grad School Chin Acad Sci, 27, pp. 755-762, 2010. 
[20] Cheng, H. H., Study on the Influence of Reservoir on the Tectonic Activities and Action Mechanism. Graduate university of Chinese Academy of Science, 2012.

[21] Sun, Y. J. and Zhang, H., et al. Study on effect of the Zipingpu reservoir on the occurrence of the 2008 Wenchuan earthquake based on a 3Dporoelastic model. Chinese J. Geophys (in Chinese), 55(7), pp. 2353-2361, 2012.

[22] Zheng, L. and Zhang, H., et al. The difference between 2D and 3D model on the effect of elastic and diffusion induced by the impoundment of Zipingpu reservoir. Earthquake (accepted, in Chinese), 2013.

[23] Cheng, H. H. and Zhang, H., et al. Finite element investigation of the poroelastic effect on the Xinfengjiang Reservoir-triggered earthquake. Science China Earth Sciences, 55(12), pp. 1942-1952, 2012.

[24] Fat-Helbary, R. E. and Tealb, A. A., A study of seismicity and earthquake hazard at the proposed Kalabsha dam site, Aswan, Egypt. Natural Hazards, 25(2), pp. 117-133, 2002.

[25] King, G. C. P. and Stein, R. S., et al. Static stress changes and the triggering of earthquakes. Bulletin of the Seismological Society of America, 84(3), pp. 935-953, 1994.

[26] Wang, M. Y. and Yang, M. Y., et al. Mechanism of the reservoir impounding earthquakes at Xingfengiiang and a preliminary endeavour to discuss their cause. Science China Earth Sciences, (1), pp. 85-97, 1976.

[27] Hu, Y. L. and Chen, X. C., Discussion on the reservoir-induced earthquakes in china and some problems related to their origin. Seismology and Geology, 4, pp. 45-57, 1979.

[28] Klose, C. D., Evidence for anthropogenic surface loading as trigger mechanism of the 2008 Wenchuan earthquake. Environmental Earth Sciences, 66(5), pp. 1439-1447, 2012.

[29] Zhou, B. and Xue, S. F., et al. Relationship between the evolution of reservoir-induced seismicity in space-time and the process of reservoir water body load-unloading and water infiltration- A case study of Zipingpu reservoir. Chinese Journal of Geophysics, 53(11), pp. 2651-2670, 2010.

[30] Zhu, B. J. and Liu, C., et al. Application of flow driven pore-network crack model to Zipingpu reservoir and Longmenshan slip. Science China Physics, Mechanics and Astronomy, 54(8), pp. 1532-1540, 2011. 